\title{
Sonic Hedgehog Regulates Discrete Populations of Astrocytes in the Adult Mouse Forebrain
}

\author{
A. Denise R. Garcia, ${ }^{1}$ Ralitsa Petrova, ${ }^{1,2}$ Liane Eng, ${ }^{1}$ and Alexandra L. Joyner ${ }^{1}$ \\ ${ }^{1}$ Developmental Biology Program, Memorial Sloan-Kettering Cancer Center, Sloan-Kettering Institute, New York, New York 10065, ${ }^{2}$ Biochemistry, Cell, and \\ Molecular Biology Program, Weill Graduate School of Medical Sciences, Cornell University, New York, New York 10065
}

\begin{abstract}
Astrocytes are an essential component of the CNS, and recent evidence points to an increasing diversity of their functions. Identifying molecular pathways that mediate distinct astrocyte functions, is key to understanding how the nervous system operates in the intact and pathological states. In this study, we demonstrate that the Hedgehog (Hh) pathway, well known for its roles in the developing CNS, is active in astrocytes of the mature mouse forebrain in vivo. Using multiple genetic approaches, we show that regionally distinct subsets of astrocytes receive $\mathrm{Hh}$ signaling, indicating a molecular diversity between specific astrocyte populations. Furthermore, we identified neurons as a source of Sonic hedgehog ( $\mathrm{Shh}$ ) in the adult forebrain, suggesting that Shh signaling is involved in neuron-astrocyte communication. Attenuation of Shh signaling in postnatal astrocytes by targeted removal of Smoothened, an obligate Shh coreceptor, resulted in upregulation of GFAP and cellular hypertrophy specifically in astrocyte populations regulated by Shh signaling. Collectively, our findings demonstrate a role for neuron-derived Shh in regulating specific populations of differentiated astrocytes.
\end{abstract}

\section{Introduction}

Emerging evidence indicates that astrocytes play active and diverse roles in the CNS. Astrocytes actively regulate cerebral blood flow (Takano et al., 2006) and respond to sensory stimuli in both the visual and somatosensory cortices (Wang et al., 2006; Schummers et al., 2008). During development, astrocytes play key roles in regulating synapse formation and function (Ullian et al., 2001) and promote maturation of dendritic spines (Nishida and Okabe, 2007). In addition, bidirectional communication between astrocytes and neurons is an important element of synaptic transmission (Zhang et al., 2003; Araque, 2008). Although it is becoming increasingly clear that astrocytes actively contribute to normal CNS function, the underlying molecular mechanisms that mediate the functional properties of astrocytes remain poorly understood.

Sonic hedgehog (Shh), a member of the Hedgehog (Hh) family of signaling proteins, is known to play critical roles in multiple aspects of CNS development. Patterning of the dorsal/ventral axis, specification of neuronal and oligodendroglial cell types, and proliferation of granule cell precursors in the cerebellum all rely on Shh signaling (Fuccillo et al., 2006). Components of this classical developmental signaling pathway are widely expressed throughout the parenchyma of the adult forebrain (Traiffort et al., 1998, 1999), but its functional significance in the adult is less well characterized. Proliferation and differentiation of adult neu-

Received Feb. 15, 2010; revised June 29, 2010; accepted July 29, 2010.

This work was supported by grants to A.L.J. from the New York State spinal cord injury research program and the National Cancer Institute (R01CA128158). We are grateful to M. Sofroniew for mGFAP-Cre mice and for critical reading of the manuscript and to T. Kelly, S. Wilson, and E. Legue for insightful discussion and critical reading of the manuscript.

Correspondence should be addressed to Alexandra L. Joyner, Developmental Biology Program, Sloan-Kettering Institute, 1275 York Avenue, Box 511, New York, NY 10065. E-mail: joynera@mskcc.org.

D01:10.1523/JNEUROSCI.0830-10.2010

Copyright $\odot 2010$ the authors $\quad$ 0270-6474/10/3013597-12\$15.00/0 ral stem cells are regulated by Shh (Balordi and Fishell, 2007a,b); however, little is known about the role of Shh signaling in cells outside the neurogenic regions.

Several lines of evidence suggest that Shh signaling could play a role in astrocyte development and/or function. In the developing optic nerve, Shh mediates proliferation of astrocyte precursors (Wallace and Raff, 1999), and application of Shh agonists to early postnatal cortical astrocyte cultures upregulates Shh target genes (Atkinson et al., 2009). In addition, the transcription factors Gli1, 2, and 3, essential components of the Shh signaling pathway, are enriched in postnatal and adult astrocyte cultures (Cahoy et al., 2008). Moreover, a recent study suggests that reactive astrocytes produce and respond to Shh following cortical freeze injury (Amankulor et al., 2009). However, it remains unknown whether astrocytes in the mature CNS participate in Shh signaling in vivo, under normal physiological conditions.

Transduction of Hh signaling is mediated by the Gli family of transcription factors, Gli1, 2, and 3. Binding of Shh to the transmembrane receptor Patched (Ptc) relieves constitutive inhibition of a second transmembrane receptor, Smoothened (Smo), thereby initiating a cascade of events leading to induction of Gli1 transcription (Fuccillo et al., 2006). Gli1 transcription in the embryo is dependent on Hh signaling through Gli2 and Gli3 (Bai et al., 2004). Thus, the presence of Gli1 can be used as an indicator of cells actively responding to high levels of Hh signaling (Bai et al., 2002).

In this study, we show that regionally distinct populations of mature, differentiated astrocytes are the primary cell type responding to Shh in the adult forebrain. We further identified neurons as a source of Shh, suggesting a novel role for Shh signaling in neuron-astrocyte communication. Finally, we demonstrate that conditional deletion of Smo in postnatal astrocytes results in a mild astrogliosis in the cortex, suggesting that Shh is an important regulator of specific astrocyte populations. 


\section{Materials and Methods}

Animals. The following mouse lines were used: Gli1 ${ }^{\text {nlacZ/+ }}$ (Bai et al., 2002), Glit ${ }^{e G F P /+}$ (B. Bai and A. L. Joyner, unpublished observations), Gli2 $^{\text {lacZ/+ }}$ (Bai et al., 2002), Gli3 $3^{\text {lacZ/+ }}$ (M. Bowers and A. L. Joyner, unpublished observations), Ptc lacZ/+ (Goodrich et al., 1997), Gli1 $^{\text {CreER/+ }}$ (Ahn and Joyner, 2005), Shh ${ }^{\text {CreER/+ }}$ (Harfe et al., 2004), Rosa26loxP-STOP-lacZ (Soriano, 1999), mGFAP-Cre (Garcia et al., 2004), and $S m o^{f l / f l}$ (Long et al., 2001). Animals were maintained on a $12 \mathrm{~h}$ light/dark cycle and allowed ad libitum access to food and water. Experiments were conducted according to protocols approved by Memorial Sloan-Kettering Cancer Center Institute for Animal Care and Use Committee and Research Animal Resource Center. Adult mice between 2 and 6 months of age were used for all experiments.

Tamoxifen. Tamoxifen (Sigma, T5648) was dissolved in corn oil to a final concentration of $20 \mathrm{mg} / \mathrm{ml}$. Adult $\mathrm{Gli1}^{\mathrm{CreER}} ;{ }^{2} 26^{\text {lacZ }}$ and $\mathrm{Shh}^{\mathrm{CreER}} ; R 26 \mathrm{R}$ animals received $0.5 \mathrm{ml}$ of tamoxifen by oral gavage for 3 consecutive days.

BrdU. BrdU (Sigma, B9285) was dissolved in $0.007 \mathrm{~N} \mathrm{NaOH}$ and administered by intraperitoneal injection. $\mathrm{Gli1}^{\mathrm{CreER}} ; \mathrm{R}^{\mathrm{lac} Z}{ }^{\text {lac }}$ animals received single injections of $200 \mathrm{mg} / \mathrm{kg} / \mathrm{d}$ for $3 \mathrm{~d}$, beginning $1 \mathrm{~d}$ after the first tamoxifen administration, and were perfused $8 \mathrm{~d}$ or 1, 3, or 6 months later. Gli $1^{\text {nlacZ/+ }}$ animals received single injections of $50 \mathrm{mg} / \mathrm{kg} / \mathrm{d}$ for $12 \mathrm{~d}$, and perfused $3 \mathrm{~d}$ later.

Perfusion and histology. Animals were given an intraperitoneal injection of sodium pentobarbital and transcardially perfused with $20-30 \mathrm{ml}$ of PBS followed by $60 \mathrm{ml}$ of $4 \%$ paraformaldehyde. Brains were dissected and postfixed for $2-4 \mathrm{~h}$, followed by cryoprotection in $30 \%$ sucrose, and stored at $4^{\circ} \mathrm{C}$ until ready for sectioning. Tissue was sectioned on a cryostat at $40 \mu \mathrm{m}$ and serial sections were collected in 96 well plates containing $0.05 \%$ sodium azide, then stored at $4^{\circ} \mathrm{C}$. Immunohistochemistry was performed on free-floating sections using the following primary antibodies, rabbit anti- $\beta$ Gal (ICN, 55976), mouse anti- $\beta$ Gal (Promega, Z3793), chicken anti-Gal (Abcam, ab9361), rabbit anti-GFAP (DAKO, Z0334), rabbit anti-S100 $\beta$ (DAKO, Z0311), mouse anti-S100 $\beta$ (Abcam ab66028), rabbit anti-glutamine synthetase (Sigma, G2781), sheep antiBrdU (Biodesign International, M20107S), sheep anti-CAII (Serotec, AHP206), mouse anti-APC-CC1 (EMD Chemicals OP80), mouse antiNeuN (Millipore Bioscience Research Reagents, MAB377), rabbit antiGFP (Invitrogen, A11122), and mouse anti-NG2 (Millipore Bioscience Research Reagents, MAB5384). For BrdU staining, sections were pretreated with $2 \mathrm{~N} \mathrm{HCl}$ for 30 min and neutralized with PBS before incubation in primary antibody. For bright-field staining, species-specific, biotinylated secondary antibodies (Vector) were used at 1:400 followed by incubation in avidin-biotin complex (ABC, Vector). Visualization was achieved using diaminobenzidine (Vector) as the developing agent. Double- or triple-labeling fluorescence immunohistochemistry was performed using species-specific, AlexaFluor-tagged secondary antibodies Alexa 488 and Alexa 555 (Invitrogen), and Cy5-conjugated secondary antibody (Jackson ImmunoResearch, 711-175-152), followed by counterstaining with DAPI (Invitrogen, D3571).

For X-gal staining, 30- $\mu \mathrm{m}$-thick brain sections were rinsed with X-gal washing buffer $\left(2 \mathrm{mM} \mathrm{MgCl}_{2}, 0.1 \%\right.$ Igepal Ca-30, 0.05\% deoxycholate in $\mathrm{PBS})$, then incubated in X-gal reaction buffer $(0.17 \mathrm{~mm}$ potassium ferrocyanide, $0.17 \mathrm{~mm}$ potassium ferricyanide, $1 \mathrm{mg} / \mathrm{ml} \mathrm{X}$-gal substrate) for $5 \mathrm{~h}$ at $37^{\circ} \mathrm{C}$. Sections were counterstained with nuclear fast red.

Microscopy. Stained sections were examined and photographed using bright-field and fluorescence microscopy using an inverted microscope (Zeiss) and Axiovision software. Single-cell analysis of coexpression was evaluated on double-stained, immunofluorescent tissues by taking optical sections with a $1 \mu \mathrm{m}$ slice distance with an Apotome (Zeiss) using a $40 \times$ objective. For each region examined, multiple $z$-stacks were collected from $2-3$ sections from each of at least 3 brains, until a minimum of 50 cells from each brain was reached. Cell counts reflect the total number of cells analyzed from all sections from all brains.

Stereological analyses and statistical evaluation. $\beta \mathrm{Gal}$ - or $\mathrm{S} 100 \beta$-labeled cells were counted in the cortex using a modified optical fractionator (Gundersen et al., 1988) and stereological image analysis software (StereoInvestigator, $\mathrm{MBF}$ Bioscience) operating a computer-driven stage attached to an upright microscope (Zeiss). Cortical analysis was limited to cortex overlying the corpus callosum, with the ventral boundaries defined as the ventromedial and ventrolateral points of the corpus callosum, and anterior and posterior boundaries defined from Figures 18 and 39, respectively, from Paxinos and Franklin (2001). One hemisphere from a minimum of 3 sections from at least 3 brains was analyzed for each group. The cortical area to be analyzed was traced at low power and counting frames were selected at random by the image analysis software. Cells were counted using a $100 \times$ objective and DIC optics. A target cell count of 300 cells was used to define scan grid and counting frame sizes, and $2 \mu \mathrm{m}$ guard zones were used. Estimated cell body volumes were determined in GFAP and S100 $\beta$-labeled cells using a nucleator probe (Møller et al., 1990; Howard and Reed, 1998) with 4 isotropic uniform random (IUR) rays emanating from the nucleus (StereoInvestigator, Microbrightfield). For analysis of GFAP-labeled cells, only cells with a clear and distinct labeled cell body were analyzed. Cells from 3 brains each for mutants and controls were analyzed using a $63 \times$ oil objective and DIC optics. Statistical evaluations were performed using Prism (GraphPad).

\section{Results}

\section{Gli1 is expressed in many nonproliferating cells in the adult forebrain}

To examine the distribution and identity of Hh-responding cells in the adult forebrain, we used Gli1 ${ }^{\text {nlacZ/+ }}$ mice in which nuclear lacZ is expressed from the Gli1 locus (Bai et al., 2002). In the developing neural tube, Gli1 is expressed predominantly in ventral populations of proliferating neuronal and oligodendrocyte precursors (Platt et al., 1997; Jessell, 2000). In contrast, we found that Gli1-expressing cells were distributed in the adult forebrain as far dorsally as the cortex, where they were localized primarily to layers 3, 4, and 5 (Fig. 1A). Dense populations of Gli1expressing cells were also found in multiple basal forebrain nuclei, including the septum (data not shown) and globus pallidus, as well as in the thalamus, and hypothalamus (Fig. $1 B-D$ ). These results are consistent with a previous report that Ptc and Smo mRNA can be detected in the globus pallidus, thalamus, and hypothalamus of the adult rat (Traiffort et al., 1999). However, whereas low levels of Ptc transcript were detected only in the piriform cortex (Traiffort et al., 1999), our findings indicate that cells in the entorhinal, motor, and somatosensory cortex express Gli1, suggesting a more widespread cortical distribution of Hh-responding cells.

Shh signaling plays a critical role in regulating adult neural stem and progenitor cells in the adult forebrain (Han et al., 2008). Although constitutive neurogenesis does not occur outside the subependymal zone (SEZ) and subgranular zone, glial progenitors proliferate throughout the parenchyma of the adult CNS (Nishiyama et al., 2002; Dawson et al., 2003). To examine whether Gli1-expressing cells outside the neurogenic regions correspond to glial progenitors, we used a second line of mice in which an inducible Cre recombinase $\left(\mathrm{CreER}^{\mathrm{T} 2}\right)$ is expressed from the Gli1 locus (Gli1 ${ }^{\mathrm{CreER} /+}$ ) (Ahn and Joyner, 2005). When combined with the Rosa26 loxP-STOP-loxP-lacZ reporter allele $\left(R 26^{\text {lac } Z}\right)$ (Soriano, 1999), cells expressing CreER $^{\mathrm{T} 2}$ from the Gli1 locus express lac $Z$ following tamoxifen administration. Lac $Z$ expression is permanent and heritable, and because CreER is active for only $\sim 36 \mathrm{~h}$ (Nakamura et al., 2006), expression of the $\beta \mathrm{Gal}$ reporter protein becomes a permanent marker of cells that were expressing Gli1 at the time of tamoxifen administration. Moreover, because $\beta \mathrm{Gal}$ expression is cytoplasmic, it is possible to examine the morphology of marked cells.

We marked Gli1-expressing cells in adult $\mathrm{Gli1}^{\mathrm{CreER} /+}$ animals that were homozygous for the reporter allele $\left(\right.$ Gli $^{\text {CreER }} ; R_{2} 6^{\text {lacZ }}$ ) by administering tamoxifen for 3 consecutive days. We then examined $\beta$ Gal expression in the cortex $8 \mathrm{~d}$, and 1,3 , and 6 months 

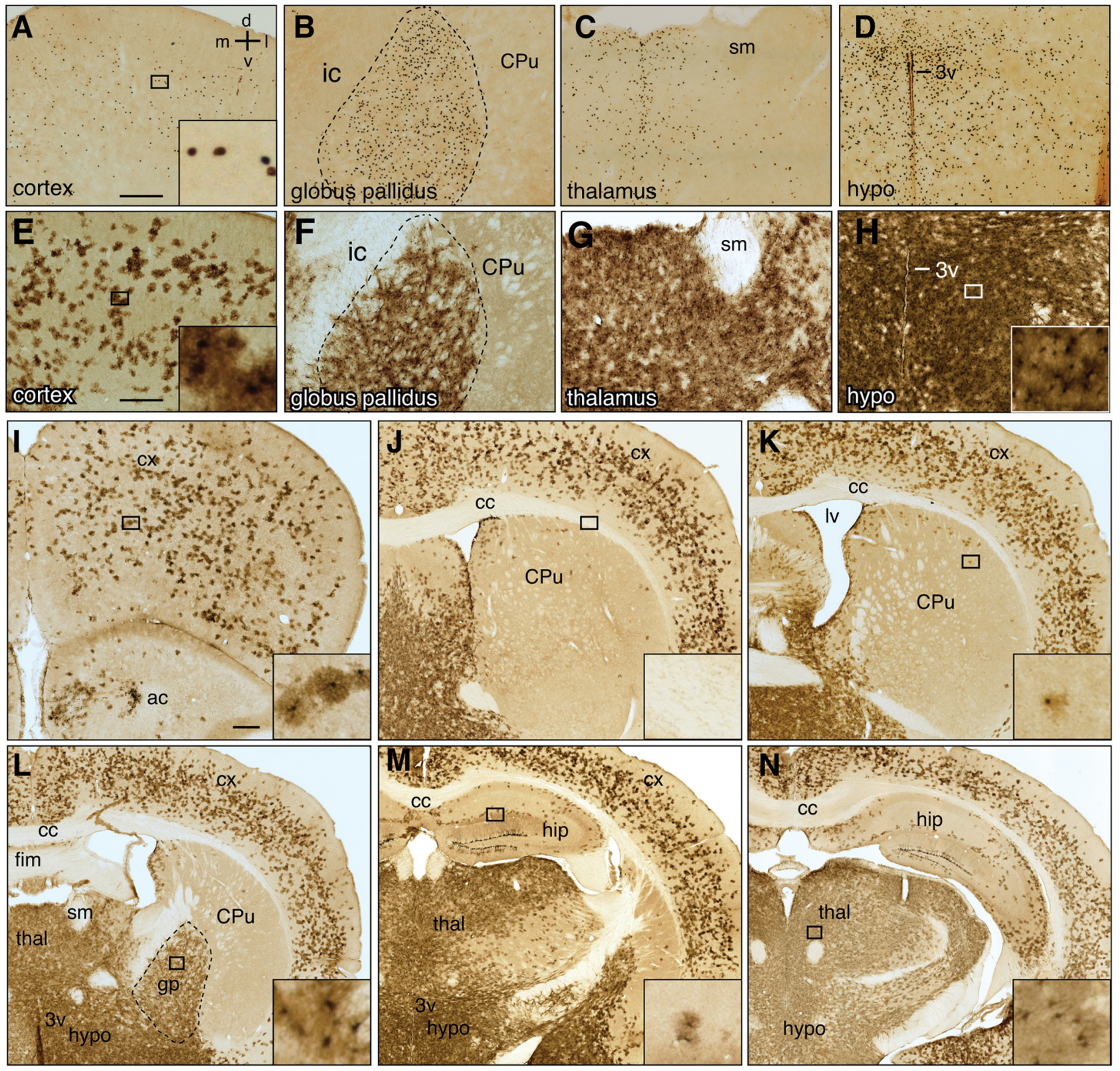

Figure 1. Gli1-expressing cells are differentially distributed throughout the $D / V$ and $A / P$ axes of the adult forebrain. $\boldsymbol{A}-\boldsymbol{H}$, Bright-field immunohistochemistry for $\beta G a l$ in the cortex $(\boldsymbol{A}, \boldsymbol{E})$, globus

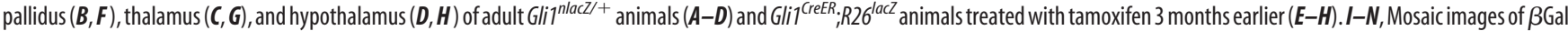
immunohistochemistry in tamoxifen-treated $\mathrm{Gli}^{(\text {rreER }} ;{ }_{2} 26^{\text {lacZ }}$ animals shows a broad distribution of Gli1-expressing cells throughout the adult forebrain. Images were constructed from multiple photomicrographs tiled together to show a single hemisphere. Note that specific regions contain little to no Gli1-expressing cells, such as the corpus callosum (cc, $J$ ), fimbria (fim, $\boldsymbol{L}$ ), caudateputamen $(\mathrm{CPu}, J)$, and hippocampal formation (hip, $\boldsymbol{M})$. Compass in $\boldsymbol{A}$ indicates dorsal $(\mathrm{d})$, ventral $(\mathrm{v})$, medial $(\mathrm{m})$, and lateral $(\mathrm{I})$. Insets show individual, labeled cells from regions indicated by the box. Dashed lines in $\boldsymbol{B}$ and $\boldsymbol{F}$ outline the globus pallidus. All images taken at $10 \times$. ac, Anterior commissure; sm, stria medullaris; $x$, cortex; Iv, lateral ventricle; thal, thalamus; gp, globus pallidus; hypo, hypothalamus; 3v, third ventricle. Scale bars, $250 \mu \mathrm{m}$.

after tamoxifen. In addition, the dividing cell marker, BrdU was administered for $3 \mathrm{~d}$ beginning $1 \mathrm{~d}$ after the first tamoxifen treatment (Fig. $2 B$ ). At day 8 after tamoxifen, we detected fewer $\beta \mathrm{Gal}-$ expressing cells in the cortex than at later time points (Fig. $2 C-F$ ). In contrast, there was no apparent increase in the number of marked cells between 1, 3, and 6 months after tamoxifen (Fig. $2 D-F)$, suggesting that Gli1-expressing cells outside the neurogenic regions are not proliferating. Interestingly, the level of $\beta \mathrm{Gal}$ in cells increased dramatically between $8 \mathrm{~d}$ and 3 months after tamoxifen, while staining intensity remained constant between 3 and 6 months after tamoxifen (Fig. $2 E, F$ ). These results suggest that an accumulation of $\beta$ Gal protein in $G l i 1^{C r e E R} ; R 26^{\text {lacZ }}$ mice is necessary before all cells marked by tamoxifen induction can be detected, and that this accumulation stabilizes after 3 months. The regional distribution of marked cells was the same at all time points (data not shown). Notably, marked cells in Gli1 ${ }^{\text {CreER} \text {; }}$ $R 26^{\text {lac } Z}$ animals were found in the same regions as observed in Gli $^{\text {nlacZ/+ }}$ animals (Fig. $1 A-H$ ). Specifically, multiple cortical regions, including the prefrontal (Fig. $1 E, I$ ), motor, somatosensory, and cingulate cortex (Fig. $1 J-N$ ), contained many $\beta$ Galpositive cells, as did the globus pallidus, thalamus, and hypothalamus (Fig. $1 F-H$ ). Interestingly, white matter tracts, including the corpus callosum, fimbria, and anterior commissure, were devoid of any $\beta \mathrm{Gal}$-expressing cells in both Gli1 ${ }^{\text {nlacZ/+ }}$ 


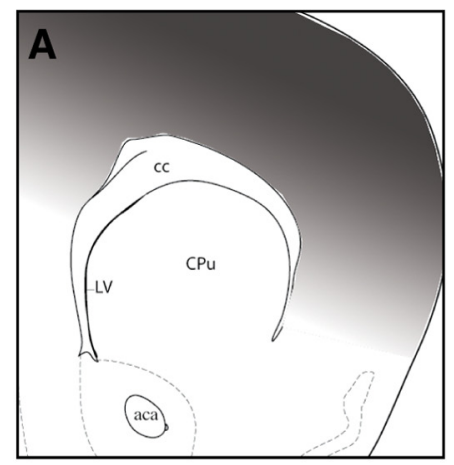

B
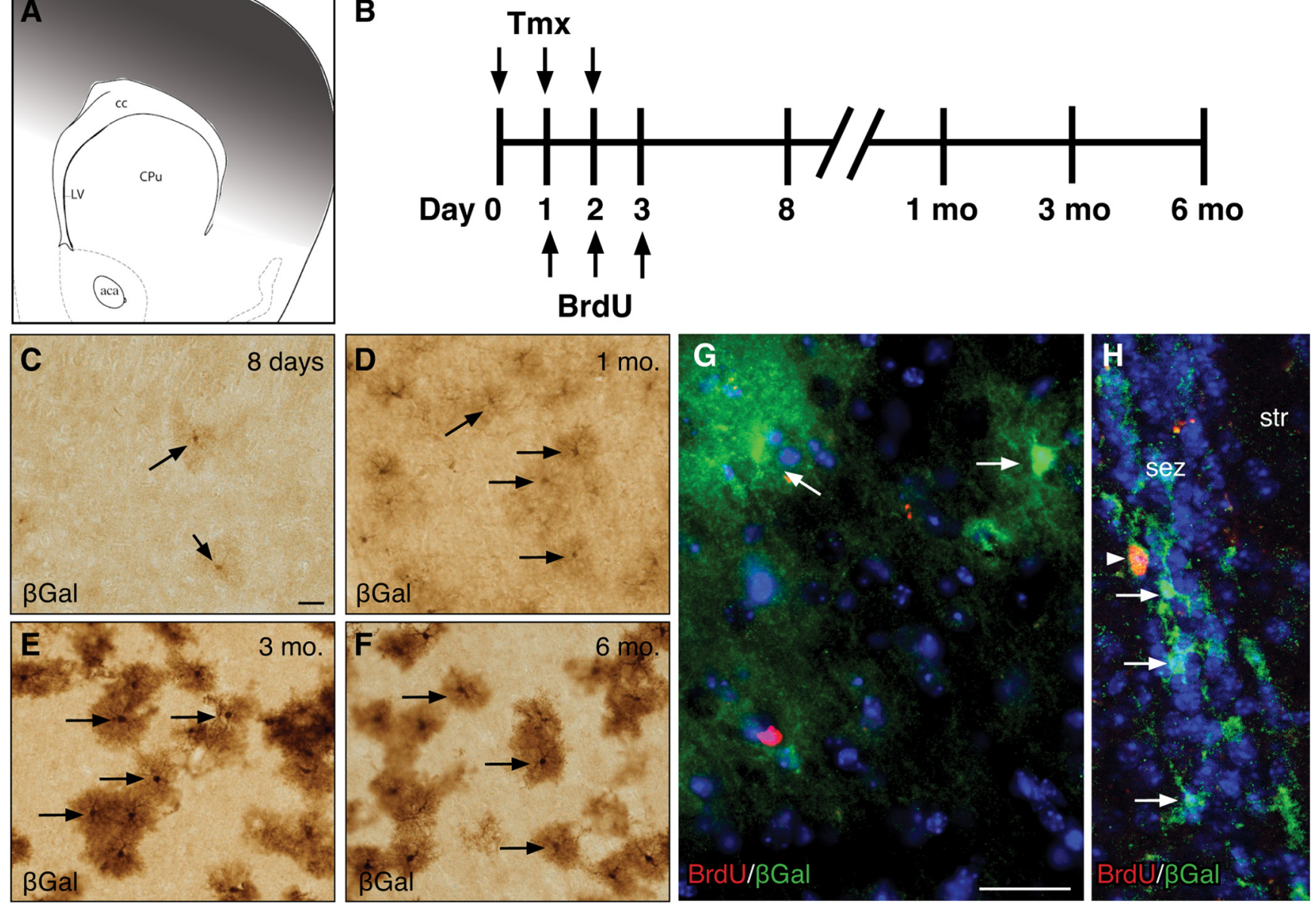

Figure 2. Gli1-expressing cells in the cortex are a stable population. $\boldsymbol{A}$, Schematic depicting the approximate A/P level of pictures shown in $\mathbf{C}-\boldsymbol{F}$. Sections up to $960 \mu \mathrm{m}$ posterior to level shown were examined. Shaded area indicates cortical region from which cells were analyzed. $\boldsymbol{B}$, Schematic of experimental protocol for tamoxifen and BrdU administration to adult Gli ${ }^{\text {(reER/+ }} ; R 26^{\text {lac } Z}$ animals. $\left(-\boldsymbol{F}\right.$, Bright-field immunohistochemistry for $\beta G$ al in the cortex of $G$ li $7^{\text {(reeR/ } /+} ; R 26^{\text {lac }}$ animals given tamoxifen, and examined on day $8(\boldsymbol{C}), 1$ month $(\boldsymbol{D}), 3$ months $(\boldsymbol{E})$, and 6 months $(\boldsymbol{F})$ after tamoxifen. $\mathbf{G}, \boldsymbol{H}$, Double-labeling immunohistochemistry for BrdU (red) and $\beta$ Gal (green) in the cortex (G) and SEZ $(\boldsymbol{H})$ of an adult $\mathrm{Gli}{ }^{\mathrm{CreER} /+} ; \mathrm{R} 26^{\mathrm{lacZ}}$ animal at 3 months after tamoxifen. All sections were counterstained with DAPI (blue). Some $\beta$ Gal cells in the SEZ, but not in the cortex, colabel with BrdU (yellow, arrowhead). Arrows indicate single-labeled $\beta G a l$ cells. Scale bars, $25 \mu \mathrm{m}$.

(data not shown) and $\mathrm{Gli1}^{\mathrm{CreER}} ; \mathrm{R} 26^{\text {lacZ }}$ (Fig. $1 \mathrm{~J}-\mathrm{N}$ ) mice, and the caudate-putamen and hippocampus exhibited only a few scattered cells (Fig. $1 J-N$ ).

The absence of an apparent expansion of marked cells between 1 and 6 months after tamoxifen suggested that Gli1expressing cells are not proliferating. Consistent with this, analysis of double staining for $\mathrm{BrdU}$ and $\beta \mathrm{Gal}$ in the cortex showed that $\beta$ Gal-expressing cells were not double labeled with BrdU at all time points examined (Fig. $2 G$ ). As expected, doublelabeled cells were readily observed in the SEZ (Fig. $2 H$ ), corresponding to adult neural stem and progenitor cells (Ahn and Joyner, 2005). However, since BrdU-labeled cells were only rarely observed in the cortex, we could not rule out the possibility that some Gli1-expressing cells divided, but escaped detection due to insufficient BrdU. We therefore used a more extensive BrdU labeling protocol that has been shown to label glial progenitor cells throughout the adult forebrain and spinal cord (Horner et al., 2000). Adult Gli1 $1^{\text {nlacZ/+ }}$ animals were given $50 \mathrm{mg} / \mathrm{kg}$ BrdU for $12 \mathrm{~d}$, and examined $3 \mathrm{~d}$ after the last BrdU injection. Despite a greater number of BrdU-labeled cells than in the previous experiments, none of the cortical BrdU-positive cells coexpressed $\beta \mathrm{Gal}$ ( $n=148$ cells) (supplemental Fig. 1, available at www.jneurosci. org as supplemental material). Glial progenitors in the adult forebrain and spinal cord express the proteoglycan, NG2 (Horner et al., 2000). Analysis of $\beta \mathrm{Gal}$ and NG2 double labeling showed that none of the $\beta \mathrm{Gal}$-expressing cells corresponded to NG2-positive glial progenitor cells (supplemental Fig. 1, available at www. jneurosci.org as supplemental material). The apparent increase in $\beta \mathrm{Gal}$-expressing cells between day 8 and 1 month after tamoxifen in $\mathrm{Gli1}^{\mathrm{CreER}} ; \mathrm{R}_{26^{\text {lacZ }}}$ forebrains therefore cannot be due to proliferation of glial progenitors, but instead must be due to accumulation of $\beta \mathrm{Gal}$ protein within cells. Together, these data suggest that, with the exception of adult neural stem and progenitor cells, the vast majority of Gli1-expressing cells in the adult forebrain are terminally differentiated. Moreover, the regional distribution of cells expressing Glil indicates that Hh signaling occurs in discrete cell populations throughout the dorsal/ventral and anterior/posterior axes.

\section{Regionally distinct populations of astrocytes express Gli1}

We next examined the cell types that express Gli1 in the adult forebrain. We primarily analyzed $\mathrm{Gli}^{\mathrm{CreER}} ; R 26^{\text {lacZ }}$ animals because the cytoplasmic localization of $\beta \mathrm{Gal}$ permitted morphological analysis. In addition, since our previous experiments indicated that reporter expression stabilizes by 3 months after tamoxifen, we restricted our analysis to adult $\mathrm{Gli}^{\mathrm{CreER}} ; \mathrm{R}_{2} 6^{\text {lac } Z}$ animals given tamoxifen 3 months earlier. Throughout the cortex, Gli1-expressing cells exhibited small cell bodies with an elab- 

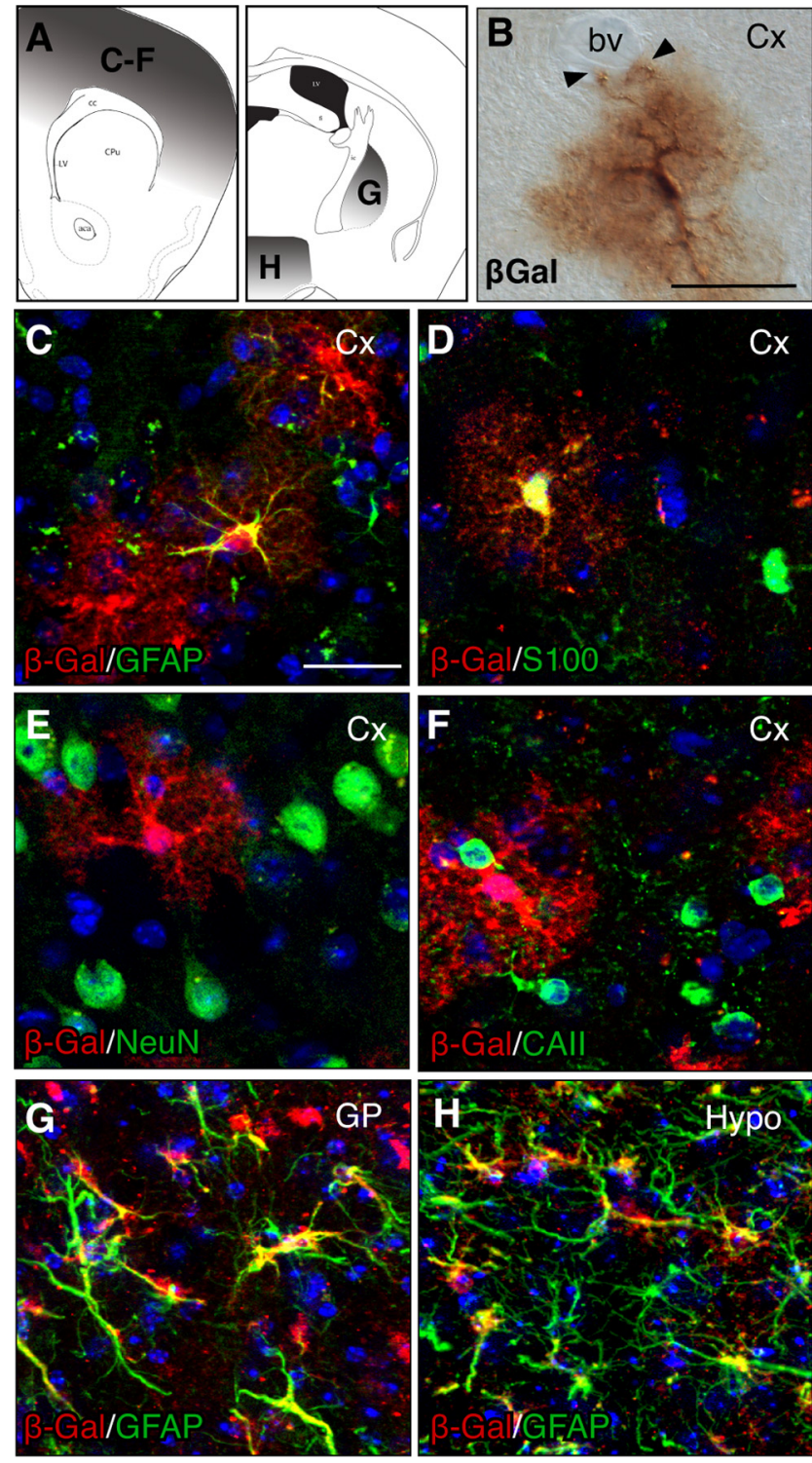

Figure 3. Gli1-expressing cells in the mature forebrain are astrocytes. $\boldsymbol{A}$, Schematics depicting approximate $A / P$ levels used for analysis. Shaded areas depict regions from which cells were analyzed. $\boldsymbol{B}$, Bright-field immunohistochemistry for $\beta$ Gal in the cortex of an adult Gli1 ${ }^{\text {CreER }}$. $R 26^{\text {lac } Z}$ animal given tamoxifen 3 months earlier. Note the bushy morphology of the processes and the nearby blood vessel (bv) contacted by the end feet (arrowheads). $\boldsymbol{C}-\boldsymbol{F}$, Double labeling with $\beta$ Gal (red) and GFAP $(\boldsymbol{C}), \operatorname{S100} \beta(\boldsymbol{D}) \operatorname{NeuN}(\boldsymbol{E})$, or CAll $(\boldsymbol{F}$, green) in the cortex shows that marked cells correspond to astrocytes. $\beta G$ al does not colocalize with the neuronal marker, NeuN, and only rarely colocalizes with the oligodendrocyte marker, CAll. $\boldsymbol{G}, \boldsymbol{H}$, Double staining with $\beta G$ al (red) and GFAP (green) showing that marked cells in the globus pallidus (G) or hypothalamus $(\boldsymbol{H})$ are also astrocytes. All sections were counterstained with DAPI (blue). Scale bar, $25 \mu \mathrm{m}$.

orate branching morphology (Figs. $1 I, 3 B$ ). The processes were highly ramified and very fine, creating a bushy appearance, consistent with the morphology of protoplasmic astrocytes. In addition, some labeled cells extended processes to nearby blood vessels (Fig. 3B), further suggesting that these cells correspond to astrocytes.

We performed double-labeling immunohistochemistry for $\beta \mathrm{Gal}$ and multiple cell type-specific markers to determine the identity of Gli1-expressing cells in the cortex. Many $\beta$ Gal-labeled cells coexpressed the astrocyte-specific marker glial fibrillary acidic protein (GFAP) (Fig. 3C). However, since relatively few astrocytes express GFAP under normal conditions (Stichel et al.,
1991; Walz, 2000), we also examined colocalization of $\beta \mathrm{Gal}$ and the pan-astrocytic marker S100 $\beta$ (Ludwin et al., 1976; Cahoy et al., 2008), which is localized to the cell body, making assessment of double labeling with $\beta \mathrm{Gal}$ more reliable. Single-cell analysis of $\beta \mathrm{Gal}$-positive cells indicated that $98.1 \%(n=468$ cells $)$ of cortical Gli1-expressing cells colabeled with $\mathrm{S} 100 \beta$ (Fig. 3D). Because some studies have reported expression of $S 100 \beta$ in cells of the oligodendrocyte lineage, we also examined colocalization between $\beta \mathrm{Gal}$ and a third astrocytic marker, glutamine synthetase (Herrmann et al., 2008). Consistent with our previous analyses, most $\beta \mathrm{Gal}$-labeled cells coexpressed glutamine synthetase (supplemental Fig. $2 C$, available at www.jneurosci.org as supplemental material). Analysis of $S 100 \beta$ and the oligodendrocyte marker CAII (Ghandour et al., 1980) showed that very few S100 $\beta$ cells colabeled with CAII (supplemental Fig. 2, available at www. jneurosci.org as supplemental material), ruling out high levels of nonspecific expression of $S 100 \beta$ in oligodendrocytes, and further supporting a predominantly astrocytic identity of Gli1expressing cells. Double labeling and analysis of $\beta \mathrm{Gal}$ and CAII (Fig. $3 F$ ) or APC-CC1 (supplemental Fig. 2, available at www. jneurosci.org as supplemental material) indicated that few cells coexpressed either of these oligodendrocyte markers $(1.3 \%$ of $\beta$ Gal-positive cells colabeled with CAII, $n=316$ cells) providing additional evidence that astrocytes, and not oligodendrocytes, are the predominant cells expressing Gli1 in the adult forebrain. Strikingly, no $\beta$ Gal-expressing cells in the cortex colabeled with the neuronal marker NeuN ( $n=246$ cells) (Fig. 3E). Examination of other forebrain regions containing Gli1-expressing cells, such as the globus pallidus and hypothalamus also showed a high degree of colocalization between $\beta \mathrm{Gal}$ and GFAP (Fig. 3G,H) or $\mathrm{S} 100 \beta$ (data not shown). These data indicate that the predominant cells expressing Gli1 in the adult forebrain correspond to astrocytes.

Interestingly, although the majority of Gli1-positive cells are astrocytes, not all astrocytes express Gli1. In addition, the proportion of astrocytes that express Glil differs between specific forebrain regions. In the cortex of tamoxifen-treated Gli1 ${ }^{C r e E R}$; $R 26^{\text {lac } Z}$ mice, only $24 \%$ of the $S 100 \beta$-positive cells were marked with $\beta \mathrm{Gal}(n=1932$ cells $)$, whereas $56 \%(n=1233$ cells $)$ and $80 \%$ ( $n=1489$ cells $)$ of S100 $\beta$-expressing cells in the globus pallidus and hypothalamus respectively, were $\beta$ Gal positive (Fig. $4)$. In contrast, the caudate-putamen and area CA1 of the hippocampus exhibit few $\beta$ Gal-positive cells (Fig. 1), indicating that the vast majority of astrocytes in these regions do not express Gli1. Similarly, white matter astrocytes do not express Gli1, as indicated by the lack of $\beta \mathrm{Gal}$ staining in the corpus callosum, anterior commissure, and fimbria (Fig. $1 F-J$ ). Inducible Cre lines, such as the one used in this study, provide the advantage of temporal control over recombination. However, it is possible that incomplete recombination might account for some of the astrocytes that appear to be Gli1-negative. Although we cannot rule out this possibility within regions containing a high proportion of Gli1-positive cells such as the cortex, it is unlikely to be the case in regions containing few or no Gli1-positive cells. The regional distribution of $\beta \mathrm{Gal}$-positive cells was similar in both Gli1 $^{\text {CreER }} ; R_{2} 6^{\text {lacZ }}$ and Gli1 $1^{\text {nlacZ/+ }}$ lines, and between all mice examined. This suggests that specific subsets of astrocytes in different regions of the forebrain are regulated by high-level $\mathrm{Hh}$ signaling.

\section{Gli1 is a sensitive readout of Shh in the adult forebrain}

Although transcriptional activation of Gli1 has been shown to be a reliable readout of Hh signaling in the developing CNS (Lee et 
al., 1997), it is possible that signaling pathways other than Hh might activate Gli1 transcription in the adult. To address whether $\mathrm{Hh}$ signaling is responsible for Gli1 expression in adult forebrain astrocytes, we took several approaches. First, we examined whether astrocytes express additional components of the Hh signaling pathway by examining $\beta \mathrm{Gal}$ expression in adult $P t c^{\text {lacZ/+ }}$ knock-in reporter mice (Goodrich et al., 1997). Since transcription of Ptc is positively regulated by Hh (Goodrich and Scott, 1998), Ptc expression can also be used as a read out of Hh activity. In adult $P t c^{\text {lac } Z /+}$ mice, many $\beta$ Gal-positive cells also expressed GFAP or $\mathrm{S} 100 \beta$ in all forebrain regions examined, including the cortex, globus pallidus, and hypothalamus (Fig. 5A-C). In addition, $\mathrm{Ptc}^{\text {lacZ/+}}$; Gli1 ${ }^{\text {GFP/+ }}$ mice showed that all Gli1-expressing cells were Ptc positive, and many Ptc-positive cells also expressed Gli1 (supplemental Fig. 3, available at www.jneurosci.org as supplemental material). Ptc-positive cells that were Gli1 negative (supplemental Fig. 3, available at www.jneurosci.org as supplemental material) exhibited a lower intensity of $\beta \mathrm{Gal}$ staining than Ptc-positive/Gli1-positive double-labeled cells (supplemental Fig. 3, available at www.jneurosci.org as supplemental material). This result is due to a lower threshold of induction for Ptc transcription by Hh signaling than Gli1. Since Gli1 transcription requires both Gli2 and Gli3, we further examined $\beta \mathrm{Gal}$ expression in Gliz ${ }^{\text {lacZ/+ }}$ (Bai et al., 2002) and Gli3 ${ }^{\text {lacZ/+ }}$

(Bowers and Joyner, unpublished) knock-in reporter mice. In both lines, $\beta$ Gal-labeled cells throughout the forebrain coexpressed GFAP or $S 100 \beta$ (Fig. $5 D-I$ ). Thus, astrocytes possess the key machinery to respond to Shh signaling.

We next disrupted Hh signaling by conditional deletion of Smo using a loxP-flanked allele $\left(S m o^{\text {loxP }}\right.$ ) (Long et al., 2001) and a transgene in which Cre expression is driven by the full-length mouse GFAP promoter ( $m$ GFAP-Cre, line 73.12) (Garcia et al., 2004). In the absence of functional Smo, Hh signaling cannot be effectively transduced within the cell, and Hh target genes, including Gli1, fail to be expressed (Long et al., 2001). In $m G F A P$ Cre; $R 26^{\text {lac } Z}$ mice, $\mathrm{X}$-gal staining shows that Cre activity is low in the forebrain at P0 and P3 (supplemental Fig. 4, available at www. jneurosci.org as supplemental material), consistent with the low levels of endogenous GFAP expression at these ages (Lewis and Cowan, 1985). At P7, there was a substantial increase in X-gal staining, and by P14 the expression pattern was similar to that seen in adult tissues (supplemental Fig. 4, available at www. jneurosci.org as supplemental material), suggesting that gene deletion in $S m o^{\text {loxP/loxP }}$; $m G F A P$-Cre mice (referred to as $m G F A P$ Smo CKO mice) begins between P0 and P7 and is largely complete by P14. GFAP expression is limited to subsets of astrocytes in the adult forebrain. However the number and distribution of labeled cells in $m G F A P-C r e ; R 26^{\text {lac } Z}$ animals was greater than that of GFAP-expressing cells. Double labeling of $\beta \mathrm{Gal}$ and S100 $\beta$ or GFAP showed that most $\beta$ Gal-positive cells are astro- cytes (supplemental Fig. 4, available at www.jneurosci.org as supplemental material). This suggests that in these mice, Cre is likely expressed in a population of early postnatal neural precursors that generate most astrocytes, thus enabling effective disruption of $\mathrm{Hh}$ signaling in both GFAP-positive and GFAPnegative astrocytes throughout the forebrain.

To monitor Gli1 expression in mGFAP-Smo CKO mice, Gli1 $^{\text {nlacZ/+ }}$ was bred onto the mutant background. mGFAP-Smo CKO mice exhibited no gross behavioral defects, and the general morphology and cytoarchitecture of the forebrain appeared normal (supplemental Fig. 5, available at www.jneurosci.org as supplemental material). Throughout the forebrains of adult mGFAP-Smo CKO;Gli1 ${ }^{\text {nlacZ/+ }}$ mice, the number of Gli1-expressing cells was dramatically lower than in littermate controls (Fig. 6). Most of the remaining Gli1-positive cells expressed both S100 $\beta$ and CAII, likely corresponding to the minor population of S100 $\beta$-expressing oligodendrocytes (supplemental Fig. 2, available at www.jneurosci.org as supplemental material) that express Gli1 in Gli1 ${ }^{\text {CreER}} ; R 26^{\text {lacZ }}$ and Gli1 ${ }^{\text {nlacZ/+ }}$ tissue. The remaining Gli1-positive cells expressed S100 $\beta$, but not CAII, suggesting that some astrocytes never express $m G F A P$-Cre and therefore do not undergo Cre-mediated recombination. Indeed, in $m G F A P-C r e$; $R 26^{\text {lacZ }}$ mice, a minor population of $S 100 \beta$-positive cells are $\beta \mathrm{Gal}$ negative (supplemental Fig. $4 E$, available at www.jneurosci.org as supplemental material). Thus, our data demonstrate that targeted deletion of Smo in $m G F A P$-Cre-expressing cells results in a 


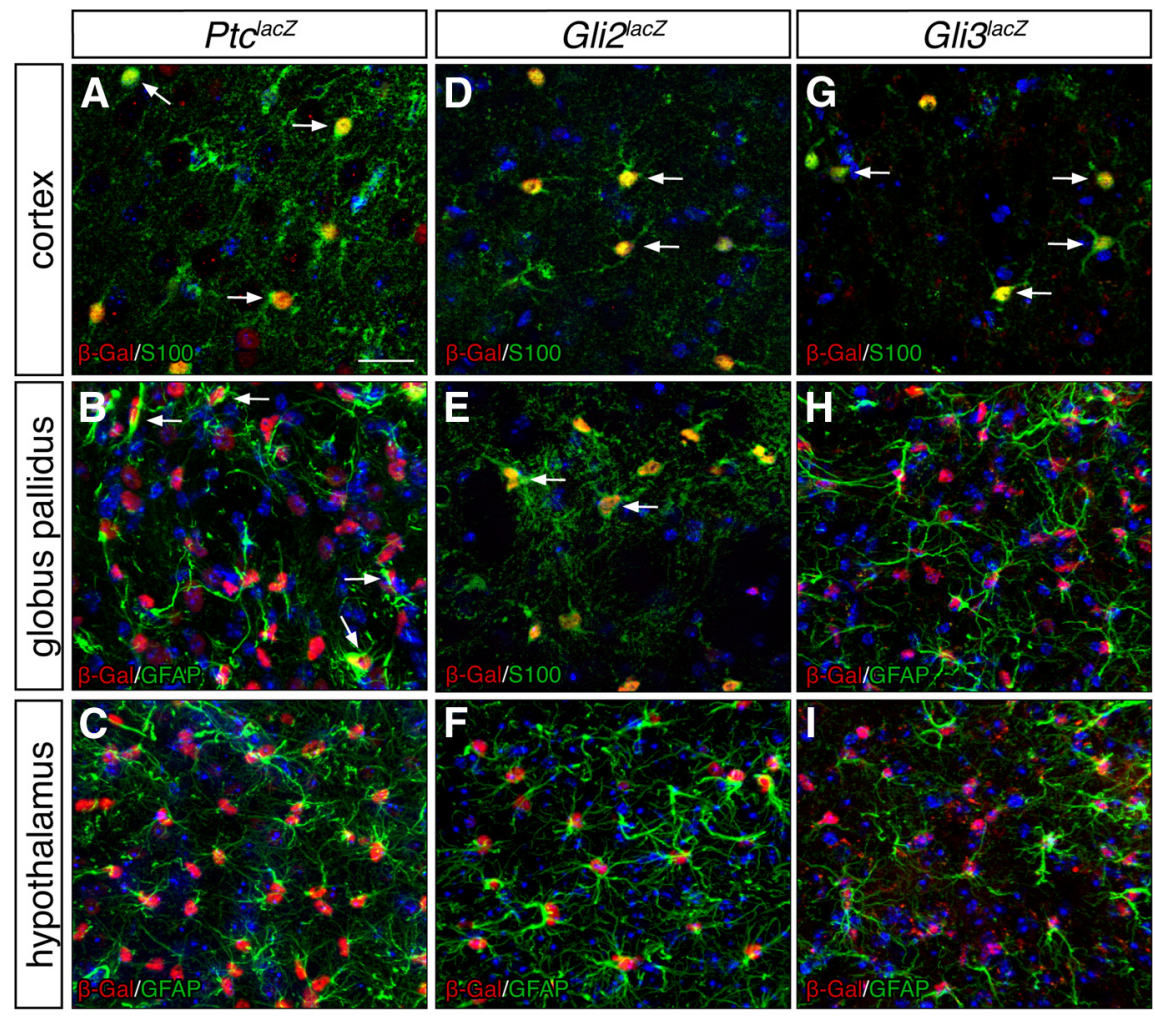

Figure 5. Astrocytes throughout the forebrain express Ptc, Gli2, and Gli3. A-C, Double-labeling immunohistochemistry for $\beta \mathrm{Gal}$ (red) and the astrocyte markers $S 100 \beta$ or GFAP (green) in the cortex $(\boldsymbol{A})$, globus pallidus $(\boldsymbol{B})$, and hypothalamus $(\boldsymbol{C})$ from adult Ptd ${ }^{\text {lacz/+ }}$ animals shows that many astrocytes express Ptc (arrows). D-F, Double-labeling for $\beta$ Gal (red) and S100 $\beta$ or GFAP (green) in adult Gli2 ${ }^{\text {lacz/+ }}$ animals. G-I, Double-labeling for $\beta$ Gal (red) and S100 $\beta$ or GFAP (green) in adult Gli3 ${ }^{\text {lacz/+ }}$ animals. All tissues were counterstained with DAPI (blue). Scale bar, $25 \mu \mathrm{m}$.

dramatic reduction in Glil expression in astrocytes, suggesting that Gli1 transcription is dependent on Smo, and is a sensitive readout of Shh signaling.

To address whether Shh is a critical ligand for Glil transcription in astrocytes, we analyzed mice heterozygous for a null mutation in Shh (Shh ${ }^{C r E E R}$ ) (Harfe et al., 2004), which thus have reduced levels of Shh. There were significantly fewer $\beta \mathrm{Gal}$ positive cells in $\mathrm{Shh}^{\mathrm{CreER} /+} ; \mathrm{R}^{2} 6^{\mathrm{YFP} /+} ; \mathrm{Gli1}^{\text {nlacZ/+}}$ mutant mice

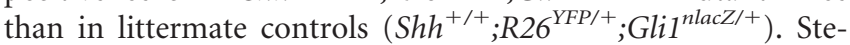
reological quantification of the number of $\beta \mathrm{Gal}$-positive cells in the cortex indicated an $80 \%$ reduction in the number of Gli1expressing cells in mutant $(36,641$ cells, $n=5)$ versus control $(165,088$ cells, $n=4)$ mice (Fig. $6 G)(p<0.01)$. While the other vertebrate homologs of $\mathrm{Hh}$, Indian hedgehog (Ihh) and Desert hedgehog (Dhh), can activate Gli1 transcription, only Shh has been shown to be highly expressed in the adult CNS (Traiffort et al., 1998). Thus, the reduction in the number of Glil-expressing cells in mice with reduced Shh suggests that only a small number of astrocytes can respond to a reduction in Shh in the forebrain. Together, these data demonstrate that Gli1 expression in adult forebrain astrocytes is activated specifically by Shh.

\section{Neurons express Shh in the adult forebrain}

To identify the source of Shh ligand in the adult forebrain, we marked Shh-expressing cells in the brains of adult Shh ${ }^{\mathrm{CreER}}$; $R 26^{\text {lacZ }}$ or $S h h^{\text {CreER }}$;R2 $6^{\text {YFP }}$ mice, and examined $\beta$ Gal or GFP expression 1 month after tamoxifen. In contrast to Gli $^{\text {CreER }} ; R 26^{\text {lac } Z}$ animals in which the staining intensity of $\beta \mathrm{Gal}$-positive cells was relatively weak at 1 month after tamoxifen, $S h h^{\text {CreER }} ; R 26^{\text {lac } Z}$ mice exhibited strong immunoreactivity for $\beta \mathrm{Gal}$ even at 1 month after tamoxifen (Fig. 7). This suggests that following Cre-mediated recombination, expression of lac $Z$ from the $R 26$ promoter is differentially regulated in various cell types. Indeed, it has been reported that lac $Z$ expression from the $R 26$ allele is poor in astrocytes, whereas fate-mapped neurons exhibit strong immunoreactivity for $\beta \mathrm{Gal}$ (Zhuo et al., 2001; Malatesta et al., 2003).

Analysis of $\beta \mathrm{Gal}$ or GFP staining showed that Shh-expressing cells in the cortex were localized primarily to layer $4 / 5$ (Fig. 7A), although a small number of cells were found in layer 2 (data not shown). In addition, basal forebrain nuclei, such as the globus pallidus and medial septum, as well as the hypothalamus and amygdala, exhibited a large number of Shh-expressing cells (supplemental Fig. 6, available at www.jneurosci.org as supplemental material), consistent with the high density of Gli1-expressing cells in these regions (Fig. 1). Interestingly, marked cells exhibited a neuronal morphology, and double staining with NeuN confirmed their neuronal phenotype (Fig. $7 B-D)$. Eighty-one percent of the Shhexpressing cells throughout the forebrain were double labeled with $\mathrm{NeuN}(n=377$ cells from 5 animals). Although some marked cells did not express NeuN, those cells nevertheless exhibited a clear neuronal morphology (supplemental Fig. 6, available at www. jneurosci.org as supplemental material). Thus, our data indicate that neurons are the source of Shh in the mature forebrain.

\section{Astrocytes in Gli1-expressing regions of the forebrain show} signs of mild reactive gliosis following postnatal interruption of Shh signaling

During development, Shh plays a critical role in specification of neuronal and oligodendrocyte precursors (Jessell, 2000). Shh has also been implicated in regulating proliferation of astrocytes in the developing optic nerve (Wallace and Raff, 1999; Dakubo et al., 2008). To investigate whether Shh plays a role in generating forebrain astrocytes, we examined $\mathrm{S} 100 \beta$ staining in $m G F A P$ Smo CKO mice. Since many astrocytes in the intact CNS do not express GFAP, and because GFAP, when expressed in normal astrocytes, is localized primarily to processes and rarely labels cell bodies, quantification based on GFAP expression is not a reliable measure of the total number of astrocytes. Thus, the number of astrocytes in mGFAP-Smo CKO mutants and controls was evaluated based on qualitative and quantitative analysis of $\mathrm{S} 100 \beta$ labeled cells. Stereological quantification of S100 $\beta$-expressing cells in the cortex of $m G F A P-S m o$ CKOs indicated no difference in the number of astrocytes between mutants (430,076 cells, $n=$ 3 ) and littermate controls $(392,652$ cells, $n=4)$ (Fig. 8). This suggests that in contrast to astrocytes in the developing optic nerve, the production of forebrain astrocytes is not dependent on Shh signaling.

Although disruption of Shh signaling did not interfere with the number of astrocytes generated in $m G F A P-S m o C K O$ mice, immunostaining for GFAP in mGFAP-Smo CKO animals 
revealed a striking elevation in GFAP expression. mGFAP-Smo CKO animals exhibited a greater intensity of GFAP immunostaining in individual cells than littermate controls (Fig. 9A,B), as well as an increase in the number of cells expressing GFAP (Fig. 9A,B). Examination of individual cells at high magnification in the cortex revealed that many cells exhibited enlarged cell bodies and thicker GFAPstained processes (Fig. 9B, insets), suggesting that astrocytes become reactive when Shh signaling is disrupted. Importantly, the upregulation of GFAP was specific to forebrain regions that normally contain many Gli1-positive cells, such as the cortex and the globus pallidus (Fig. $9 A, B$ and data not shown). In contrast, the caudate-putamen, which contains few Gli1-expressing cells, showed no obvious change in GFAP expression (Fig. 9C,D).

To confirm the cellular hypertrophy observed in mGFAP-Smo CKO mutants, we measured the volume of the cell bodies of GFAP- or S100 $\beta$-stained cells in the cortex and caudate-putamen using the nucleator method (Fig. 9E,F) (Gundersen, 1988). In the cortices of mGFAP-Smo CKO mutants, there was a significant increase in volume compared to controls of both GFAP- $\left(411.7 \mu \mathrm{m}^{3}, n=157\right.$ cells and 129.4 $\mu \mathrm{m}^{3}, n=259$ cells for mutants and controls, respectively) and S100 $\beta-\left(299.6 \mu \mathrm{m}^{3}\right.$, $n=354$ cells and $159.5 \mu \mathrm{m}^{3}, n=412$ cells for mutants and controls, respectively) stained cells. In contrast, there was no difference in the volume of cells in the caudateputamen between mutants and controls for both markers (GFAP, $181.4 \mu \mathrm{m}^{3}, n=278$ cells and $172.6 \mu \mathrm{m}^{3}, n=195$ cells for mutants and controls, respectively; $\mathrm{S} 100 \beta$, $131.2 \mu \mathrm{m}^{3}, n=329$ cells and $143.9 \mu \mathrm{m}^{3}, n=371$ cells for mutants and controls, respectively). In addition, triple labeling of the few remaining Gli1-expressing cells in the cortex of mGFAP-Smo CKO; Gli1 $^{\text {nlacZ/+ }}$ animals with $\beta \mathrm{Gal}, \mathrm{S} 100 \beta$, and GFAP showed that none of the Gli1-expressing cells expressed GFAP (Fig. 6). Thus, any remaining Gli1-expressing astrocytes in mGFAP-Smo CKO mutants maintain Shh signaling and do not show signs of astrogliosis. These data demonstrate that perturbing Shh signaling in astrocytes results in specific physiological consequences, indicating an important role for Shh signaling in regulating cellular function. Moreover, the absence of cellular hypertrophy or of changes in GFAP expression in caudate-putamen astrocytes indicates a highly specific response of distinct astrocyte populations to loss of Smo.

Upregulation of GFAP and hypertrophy are hallmarks of reactive astrogliosis, which occurs in response to injury or disease (Eng and Ghirnikar, 1994). Reactive astrocytes have also been shown to undergo increased proliferation and synthesis of nestin and vimentin (Sofroniew, 2009). However, BrdU labeling showed no change in proliferation between mutants and controls (data not shown), and staining for nestin and vimentin showed no change in expression of these intermediate filaments (data not shown). Together, these data show that the cellular response to interrupting Shh signaling includes key characteristics of reactive astrogliosis and indicates that Shh signaling plays an important role in mediating intracellular properties of specific astrocyte populations.

\section{Discussion}

In this study, we show that high-level Shh signaling in the adult CNS occurs in regionally distinct populations of mature, differentiated astrocytes. Our data demonstrate that neurons are a source of Shh, suggesting a novel signaling pathway involved in direct neuron-astrocyte communication. Furthermore, we provide evidence that Shh signaling is required to maintain normal cellular functions in specific astrocyte populations. Together, our data are the first to demonstrate a critical role for Shh signaling in neuron-astrocyte communication in vivo, in the adult CNS.

The roles of Shh in regulating proliferation and differentiation of neural precursors in the developing and adult CNS are well characterized (Jessell, 2000; Fuccillo et al., 2006). However, our results show that the predominant cells receiving Shh in the adult CNS are not proliferating. Using two different BrdU labeling protocols and two transgenic mouse lines, we found no evidence for proliferation of Gli1-expressing cells localized outside the 

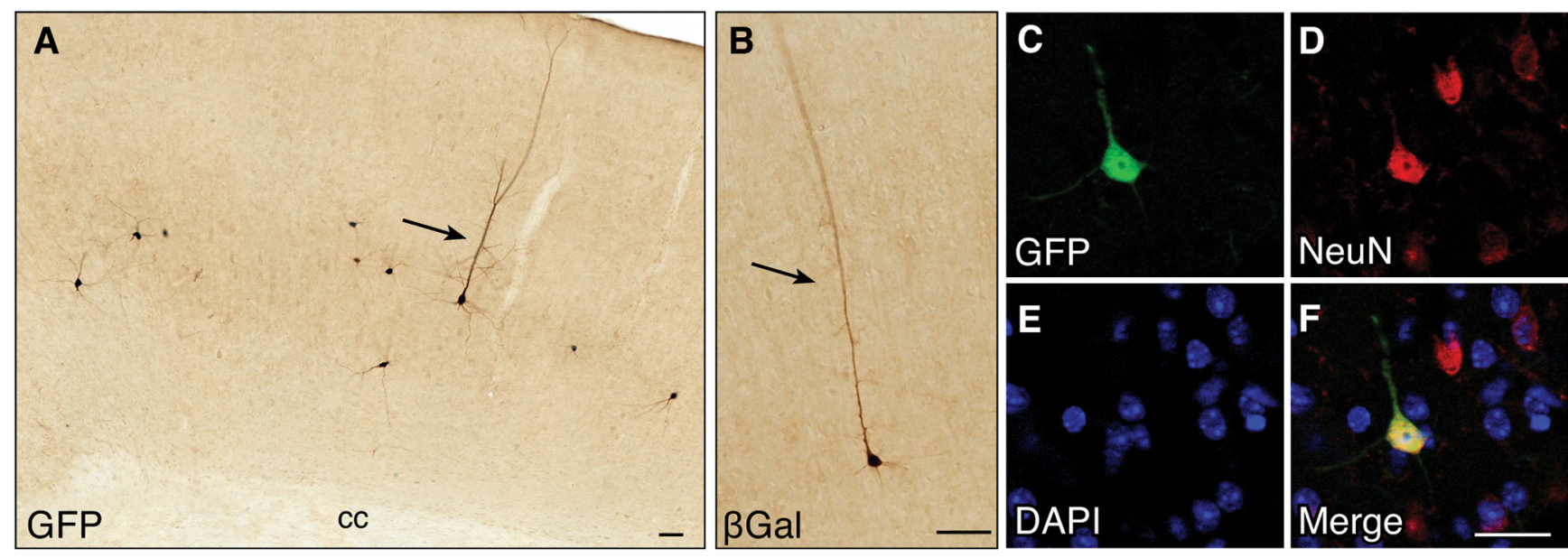

Figure 7. Neurons are a source of Shh in the forebrain. $\boldsymbol{A}, \boldsymbol{B}$, Bright-field immunohistochemistry for GFP $(\boldsymbol{A})$ or $\beta$ Gal $(\boldsymbol{B})$ in the cortex of adult Shh ${ }^{\text {CreER }} ; R 26^{\text {YFP }}$ or $\operatorname{Shh}^{\text {CreetR }} ; R 26^{\text {lacZ }}$ animals respectively, given tamoxifen 1 month earlier. Note that GFP and $\beta$ Gal are expressed in the processes showing the neuronal morphology of marked cells (arrows). $\mathbf{C} \boldsymbol{F}$, Single optical sections of double labeling for GFP (green, $\boldsymbol{C}$ ) and NeuN (red, $\boldsymbol{D}$ ) in the cortex of an adult Shh ${ }^{\text {CreER }} ; R 26^{\gamma F P}$ animal showing that marked cells colabel with the mature neuronal marker, NeuN. All sections were counterstained with DAPI (blue, $\boldsymbol{E}$ ). Merged image is shown in $\boldsymbol{F}$. Scale bars: $\boldsymbol{A}, \boldsymbol{B}, 50 \mu \mathrm{m} ; \boldsymbol{C}-\boldsymbol{F}, 25 \mu \mathrm{m}$.
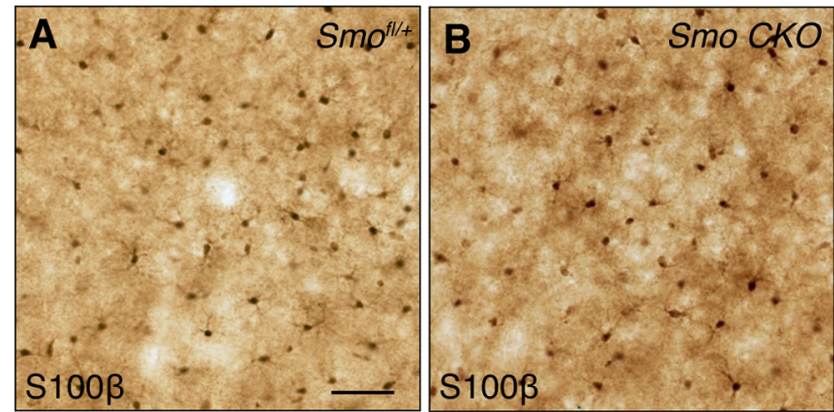

\section{C}

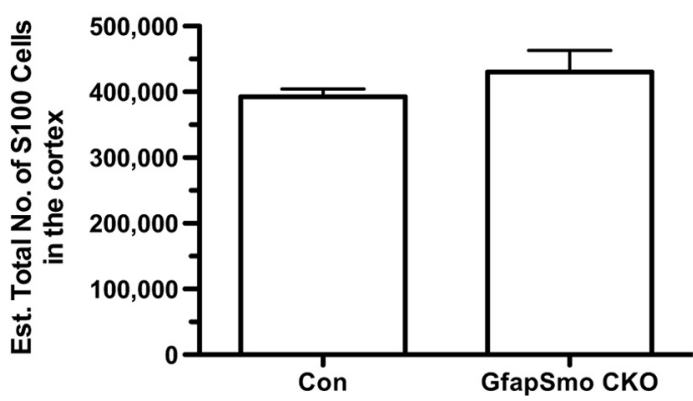

Figure 8. Conditional deletion of Smo does not change the number of astrocytes. $\boldsymbol{A}, \boldsymbol{B}$, Bright-field immunostaining for $S 100 \beta$ in the cortex shows no difference in the number of astrocytes in $M G F A P$-Smo CKO animals (B) compared to littermate controls $(\boldsymbol{A})$. C, Quantification of the number of cortical astrocytes in mGFAP-Smo CKO animals and littermate controls (mean \pm SEM; control, $n=4, m G F A P$-Smo CKO, $n=3$, unpaired $t$ test). Scale bar, $50 \mu \mathrm{m}$.

neurogenic regions of the adult forebrain. Our finding that the number of marked cells in Gli1 ${ }^{\mathrm{CreER}} ; \mathrm{R}_{2} 6^{\text {lac } Z}$ mice remains constant between 1 and 6 months after tamoxifen further supports the idea that Shh signals primarily to differentiated cells in the adult CNS.

Although GFAP-expressing adult neural stem cells have been shown to respond to Shh (Ahn and Joyner, 2005; Balordi and Fishell, 2007a,b), the vast majority of Gli1-expressing cells in the adult forebrain are postmitotic, protoplasmic astrocytes. The identification of astrocytes as the predominant cell population expressing Gli1 was based on expression of well known astrocytespecific markers, GFAP, $\mathrm{S} 100 \beta$, and glutamine synthetase. $\mathrm{S} 100 \beta$ expression has been reported in oligodendrocyte precursors or in myelinating oligodendrocytes of the white matter (Hachem et al., 2005). However, mature oligodendrocytes in cortical gray matter downregulate $\mathrm{S} 100 \beta$ (Dyck et al., 1993), and our own analysis of $\mathrm{S} 100 \beta$ and CAII in the cortex indicated a low incidence of colocalization between these two markers. The astrocytic identity of Gli1-expressing cells is further supported by the morphology of marked cells in Gli $^{C r e E R} ; R 26^{\text {lacZ }}$ mice. Although we cannot rule out noncanonical mechanisms of Shh signaling, our data demonstrate that in the adult forebrain, astrocytes are the predominant cells using Gli1-mediated Shh signaling.

Astrocytes are comprised of cells with diverse characteristics. They exhibit varying morphologies (Emsley and Macklis, 2006), and differ in their expression of intermediate filaments such as GFAP and vimentin (Eng et al., 2000; Kimelberg, 2004). In this study, we demonstrate that regionally distinct populations of astrocytes express Gli1, showing an additional layer of astrocyte diversity based on underlying signaling mechanisms. The molecular and morphological diversity that characterizes different neuronal populations has long been the basis of important functional differences between distinct neuronal classes. The diversity of astrocytes and the functional consequences of such diversity, however, are poorly understood. Nevertheless, a growing body of evidence supports the idea that subpopulations of astrocytes exhibit specific functional properties. In the hippocampus, subpopulations of astrocytes have been identified with distinct electrophysiological properties (Steinhäuser et al., 1992, 1994) and gap junctional coupling (Wallraff et al., 2004). In addition, astrocytes differ in their expression of glutamate receptors and transporters (Zhou and Kimelberg, 2001; Matthias et al., 2003). It is likely that intracellular signaling pathways regulate regional and/or functional identity. Our results point to Shh signaling as one mechanism by which different astrocyte populations might gain specific functional properties.

Using an antibody to $\mathrm{Sh}$, a recent report indicated that reactive astrocytes express Shh following a cortical freeze injury model (Amankulor et al., 2009). In contrast, our data show that in the uninjured CNS, neurons are the primary source of Shh signaling to astrocytes, and we found no evidence for astrocyte expression of Shh under normal, physiological conditions. All marked cells in $S h h^{C r e E R} ; R 26 R$ animals expressed the neuronal 
marker NeuN and/or exhibited a neuronal morphology. Moreover, although the ROSA promoter is weaker in astrocytes than in neurons, recombined cells with a clear astrocytic morphology are readily observed in Gli1 $^{\text {CreER }} ; R 26^{\text {lacZ }}$ animals at 1 month after tamoxifen, but not in $S h h^{\text {CreER }} ; R 26 R$ animals at the same time point (compare Fig. 6 and Fig. 2). Although we cannot exclude the possibility that astrocytes express very low levels of Shh, we find no evidence for cell autonomous, high-level Shh signaling in the uninjured forebrain.

In the developing CNS, cells expressing the Shh target gene Gli1 are localized adjacent to the source of Shh (Platt et al., 1997). Similarly, we found a major population of Gli1-expressing astrocytes in conjunction with Shh-expressing neurons in the hypothalamus. However, our data suggest that in the mature forebrain, Gli1 transcription is not necessarily dependent on local sources of Shh. In the cortex, for example, we found few Shh-expressing neurons, despite the large population of Gli1-expressing cells. It is possible that projections from subcortical Shhexpressing neurons induce cortical Gli1. In support of this hypothesis, Shh is transported axonally in the developing and adult rodent optic nerve (Wallace and Raff, 1999; Traiffort et al., 2001; Dakubo et al., 2008). Notably, Shh-expressing cells were found in the caudate (supplemental Fig. 5, available at www.jneurosci.org as supplemental material) despite a relatively low level of Gli1 expression, further suggesting that Shh does not necessarily induce local Gli1 expression.

Alternatively, signaling pathways other than Shh may be responsible for Gli1 transcription in some cells. However, several lines of evidence suggest against this explanation. First, astrocytes express all the critical components of the Shh signaling pathway, including Ptc, Gli2, and Gli3, suggesting that astrocytes possess the machinery to respond to Shh. Moreover, both reduced levels of Shh in Shh ${ }^{+/-}$ mice and targeted deletion of Smo in mGFAP-Smo CKO mutants lead to concomitant reductions in the number of Gli1-expressing cells throughout the forebrain. Together, these data provide strong evidence that Shh is the critical signal regulating Gli1 transcription. In addition, our data raise the possibility that both local and longdistance Shh signaling might occur in the adult forebrain.

Astrocytes are known to be sensitive to disturbances in CNS homeostasis, and become reactive in response to various insults to the CNS (Sofroniew, 2009). The severity of the reactive astrogliosis response is dependent on the nature and severity of the initial insult. Dramatic upregulation of GFAP and cellular hypertrophy are key characteristics of reactive astrocytes. The observation that cortical astrocytes in $m G F A P-S m o$ CKO mutants exhibit increased GFAP expression and cell volume, without concomitant changes in cell proliferation or expression of nestin or vimentin, indicates a mild gliosis in response to disruptions in Shh signaling, and suggests that Shh plays an important role in maintaining normal CNS function. Moreover, our observation that cortical, but not striatal, astrocytes exhibit reactive gliosis indicates a specific response of cortical, Gli1-expressing astrocytes to disruptions in Shh signaling. This result argues against a global defect in homeostasis in $m$ GFAP-Smo CKO mutants, and instead supports the hypothesis that neuronal-derived Shh regulates specific subsets of astrocytes in the adult forebrain.

In addition to injury or disease, it has been shown that astrocytes become reactive in response to neuronal hyperactivity (Steward et al., 1991; Torre et al., 1993). A tempting speculation, therefore, is that the reactive astrocyte phenotype observed in mGFAP-Smo CKOs reflects abnormal synaptic activity resulting from aberrant gliotransmission from mutant astrocytes to neighboring wild-type neurons. Activation of G-protein-coupled receptors (GPCRs) on astrocytes elicits $\mathrm{Ca}^{2+}$-dependent release of various gliotransmitters, including glutamate, ATP, and D-serine (Fiacco and McCarthy, 2004; Perea and Araque, 2007), which can in turn modulate neuronal activity (Pascual et al., 2005b; Fellin, 2009). Interestingly, Smo is a 7-pass transmembrane receptor, and has been shown to stimulate multiple G-proteins (Kasai et al., 2004; Masdeu et al., 2006). In addition, Shh can increase intracellular $\mathrm{Ca}^{2+}$ in mouse embryonic stem cells and rat gastric mucosal cells (Osawa et al., 2006; Heo et al., 2007). Thus, insufficient $\mathrm{Ca}^{2+}$ signaling as a result of impaired Smo function in astrocytes might lead to aberrant intercellular communication 
events between astrocytes and neurons. Subsequently, inappropriate synaptic activity due to impaired gliotransmission would feed back to neighboring astrocytes, resulting in a reactive response. In support of this hypothesis are studies demonstrating that application of Shh to brain slices reduces neuronal activity (Bezard et al., 2003; Pascual et al., 2005a). Notably, Bezard et al. (2003) only observed Shh-mediated neuronal responses after a 3 min delay, a time scale that is consistent with secondary signaling mechanisms, rather than a direct effect of Shh on neuronal ion channels. In this scenario, the molecular events that regulate astrocyte intercellular communication likely would be coincident with, but independent of, Gli1 transcription. Alternatively, Glidependent transcription might be mediating intracellular mechanisms that lead to impaired glial function and, subsequently, reactive astrocytosis. Future experiments are needed to examine whether Gli-dependent or independent mechanisms govern the intracellular events leading to the reactive astrocytosis observed in $m G F A P$-Smo CKO mutants. Our data nevertheless indicate that Shh plays an important role in intercellular communication between specific neuronal and astrocyte populations of the adult forebrain, demonstrating a novel role for Shh signaling. Moreover, our data support an emerging paradigm in which astrocytes, like neurons, are molecularly and functionally diverse.

\section{References}

Ahn S, Joyner AL (2005) In vivo analysis of quiescent adult neural stem cells responding to Sonic hedgehog. Nature 437:894-897.

Amankulor NM, Hambardzumyan D, Pyonteck SM, Becher OJ, Joyce JA, Holland EC (2009) Sonic hedgehog pathway activation is induced by acute brain injury and regulated by injury-related inflammation. J Neurosci 29:10299-10308.

Araque A (2008) Astrocytes process synaptic information. Neuron Glia Biol $4: 3-10$.

Atkinson PJ, Dellovade T, Albers D, Von Schack D, Saraf K, Needle E, Reinhart PH, Hirst WD (2009) Sonic Hedgehog signaling in astrocytes is dependent on p38 mitogen-activated protein kinase and G-protein receptor kinase 2. J Neurochem 108:1539-1549.

Bai CB, Auerbach W, Lee JS, Stephen D, Joyner AL (2002) Gli2, but not Gli1, is required for initial Shh signaling and ectopic activation of the Shh pathway. Development 129:4753-4761.

Bai CB, Stephen D, Joyner AL (2004) All mouse ventral spinal cord patterning by hedgehog is Gli dependent and involves an activator function of Gli3. Dev Cell 6:103-115.

Balordi F, Fishell G (2007a) Mosaic removal of hedgehog signaling in the adult SVZ reveals that the residual wild-type stem cells have a limited capacity for self-renewal. J Neurosci 27:14248-14259.

Balordi F, Fishell G (2007b) Hedgehog signaling in the subventricular zone is required for both the maintenance of stem cells and the migration of newborn neurons. J Neurosci 27:5936-5947.

Bezard E, Baufreton J, Owens G, Crossman AR, Dudek H, Taupignon A, Brotchie JM (2003) Sonic hedgehog is a neuromodulator in the adult subthalamic nucleus. FASEB J 17:2337-2338.

Cahoy JD, Emery B, Kaushal A, Foo LC, Zamanian JL, Christopherson KS, Xing Y, Lubischer JL, Krieg PA, Krupenko SA, Thompson WJ, Barres BA (2008) A transcriptome database for astrocytes, neurons, and oligodendrocytes: a new resource for understanding brain development and function. J Neurosci 28:264-278.

Dakubo GD, Beug ST, Mazerolle CJ, Thurig S, Wang Y, Wallace VA (2008) Control of glial precursor cell development in the mouse optic nerve by sonic hedgehog from retinal ganglion cells. Brain Res 1228:27-42.

Dawson MR, Polito A, Levine JM, Reynolds R (2003) NG2-expressing glial progenitor cells: an abundant and widespread population of cycling cells in the adult rat CNS. Mol Cell Neurosci 24:476-488.

Dyck RH, Van Eldik LJ, Cynader MS (1993) Immunohistochemical localization of the S-100 beta protein in postnatal cat visual cortex: spatial and temporal patterns of expression in cortical and subcortical glia. Brain Res Dev Brain Res 72:181-192.

Emsley JG, Macklis JD (2006) Astroglial heterogeneity closely reflects the neuronal-defined anatomy of the adult murine CNS. Neuron Glia Biol 2:175-186.

Eng LF, Ghirnikar RS (1994) GFAP and astrogliosis. Brain Pathol 4:229-237.

Eng LF, Ghirnikar RS, Lee YL (2000) Glial fibrillary acidic protein: GFAPthirty-one years (1969-2000). Neurochem Res 25:1439-1451.

Fellin T (2009) Communication between neurons and astrocytes: relevance to the modulation of synaptic and network activity. J Neurochem 108:533-544.

Fiacco TA, McCarthy KD (2004) Intracellular astrocyte calcium waves in situ increase the frequency of spontaneous AMPA receptor currents in CA1 pyramidal neurons. J Neurosci 24:722-732.

Fuccillo M, Joyner AL, Fishell G (2006) Morphogen to mitogen: the multiple roles of hedgehog signalling in vertebrate neural development. Nat Rev Neurosci 7:772-783.

Garcia AD, Doan NB, Imura T, Bush TG, Sofroniew MV (2004) GFAPexpressing progenitors are the principal source of constitutive neurogenesis in adult mouse forebrain. Nat Neurosci 7:1233-1241.

Ghandour MS, Langley OK, Vincendon G, Gombos G, Filippi D, Limozin N, Dalmasso D, Laurent G (1980) Immunochemical and immunohistochemical study of carbonic anhydrase II in adult rat cerebellum: a marker for oligodendrocytes. Neuroscience 5:559-571.

Goodrich LV, Scott MP (1998) Hedgehog and patched in neural development and disease. Neuron 21:1243-1257.

Goodrich LV, Milenković L, Higgins KM, Scott MP (1997) Altered neural cell fates and medulloblastoma in mouse patched mutants. Science 277:1109-1113.

Gundersen HJ (1988) The nucleator. J Microsc 151:3-21.

Gundersen HJ, Bagger P, Bendtsen TF, Evans SM, Korbo L, Marcussen N, Møller A, Nielsen K, Nyengaard JR, Pakkenberg B, Sørensen FB, Vesterby A, West MJ (1988) The new stereological tools: disector, fractionator, nucleator and point sampled intercepts and their use in pathological research and diagnosis. APMIS 96:857-881.

Hachem S, Aguirre A, Vives V, Marks A, Gallo V, Legraverend C (2005) Spatial and temporal expression of S100B in cells of oligodendrocyte lineage. Glia 51:81-97.

Han YG, Spassky N, Romaguera-Ros M, Garcia-Verdugo JM, Aguilar A, Schneider-Maunoury S, Alvarez-Buylla A (2008) Hedgehog signaling and primary cilia are required for the formation of adult neural stem cells. Nat Neurosci 11:277-284.

Harfe BD, Scherz PJ, Nissim S, Tian H, McMahon AP, Tabin CJ (2004) Evidence for an expansion-based temporal Shh gradient in specifying vertebrate digit identities. Cell 118:517-528.

Heo JS, Lee MY, Han HJ (2007) Sonic hedgehog stimulates mouse embryonic stem cell proliferation by cooperation of $\mathrm{Ca} 2+$ /protein kinase $\mathrm{C}$ and epidermal growth factor receptor as well as Glil activation. Stem Cells 25:3069-3080.

Herrmann JE, Imura T, Song B, Qi J, Ao Y, Nguyen TK, Korsak RA, Takeda K, Akira S, Sofroniew MV (2008) STAT3 is a critical regulator of astrogliosis and scar formation after spinal cord injury. J Neurosci 28:7231-7243.

Horner PJ, Power AE, Kempermann G, Kuhn HG, Palmer TD, Winkler J, Thal LJ, Gage FH (2000) Proliferation and differentiation of progenitor cells throughout the intact adult rat spinal cord. J Neurosci 20:2218-2228.

Howard CV, Reed MG (1998) Unbiased stereology: three-dimensional measurement in microscopy. New York: BIOS Scientific.

Jessell TM (2000) Neuronal specification in the spinal cord: inductive signals and transcriptional codes. Nat Rev Genet 1:20-29.

Kasai K, Takahashi M, Osumi N, Sinnarajah S, Takeo T, Ikeda H, Kehrl JH, Itoh G, Arnheiter H (2004) The G12 family of heterotrimeric $G$ proteins and Rho GTPase mediate Sonic hedgehog signalling. Genes Cells 9:49-58.

Kimelberg HK (2004) The problem of astrocyte identity. Neurochem Int 45:191-202.

Lee J, Platt KA, Censullo P, Ruiz i Altaba A (1997) Gli1 is a target of Sonic hedgehog that induces ventral neural tube development. Development 124:2537-2552.

Lewis SA, Cowan NJ (1985) Temporal expression of mouse glial fibrillary acidic protein mRNA studied by a rapid in situ hybridization procedure. J Neurochem 45:913-919.

Long F, Zhang XM, Karp S, Yang Y, McMahon AP (2001) Genetic manipulation of hedgehog signaling in the endochondral skeleton reveals a direct role in the regulation of chondrocyte proliferation. Development 128:5099-5108. 
Ludwin SK, Kosek JC, Eng LF (1976) The topographical distribution of S-100 and GFA proteins in the adult rat brain: an immunohistochemical study using horseradish peroxidase-labelled antibodies. J Comp Neurol 165:197-207.

Malatesta P, Hack MA, Hartfuss E, Kettenmann H, Klinkert W, Kirchhoff F, Götz M (2003) Neuronal or glial progeny: regional differences in radial glia fate. Neuron 37:751-764.

Masdeu C, Faure H, Coulombe J, Schoenfelder A, Mann A, Brabet I, Pin JP, Traiffort E, Ruat M (2006) Identification and characterization of Hedgehog modulator properties after functional coupling of Smoothened to G15. Biochem Biophys Res Commun 349:471-479.

Matthias K, Kirchhoff F, Seifert G, Hüttmann K, Matyash M, Kettenmann H, Steinhäuser C (2003) Segregated expression of AMPA-type glutamate receptors and glutamate transporters defines distinct astrocyte populations in the mouse hippocampus. J Neurosci 23:1750-1758.

Møller A, Strange P, Gundersen HJ (1990) Efficient estimation of cell volume and number using the nucleator and the disector. J Microsc 159:61-71.

Nakamura E, Nguyen MT, Mackem S (2006) Kinetics of tamoxifenregulated Cre activity in mice using a cartilage-specific CreER(T) to assay temporal activity windows along the proximodistal limb skeleton. Dev Dyn 235:2603-2612.

Nishida H, Okabe S (2007) Direct astrocytic contacts regulate local maturation of dendritic spines. J Neurosci 27:331-340.

Nishiyama A, Watanabe M, Yang Z, Bu J (2002) Identity, distribution, and development of polydendrocytes: NG2-expressing glial cells. J Neurocytol 31:437-455.

Osawa H, Ohnishi H, Takano K, Noguti T, Mashima H, Hoshino H, Kita H, Sato K, Matsui H, Sugano K (2006) Sonic hedgehog stimulates the proliferation of rat gastric mucosal cells through ERK activation by elevating intracellular calcium concentration. Biochem Biophys Res Commun 344:680-687.

Pascual O, Traiffort E, Baker DP, Galdes A, Ruat M, Champagnat J (2005a) Sonic hedgehog signalling in neurons of adult ventrolateral nucleus tractus solitarius. Eur J Neurosci 22:389-396.

Pascual O, Casper KB, Kubera C, Zhang J, Revilla-Sanchez R, Sul JY, Takano H, Moss SJ, McCarthy K, Haydon PG (2005b) Astrocytic purinergic signaling coordinates synaptic networks. Science 310:113-116.

Paxinos G, Franklin KBJ (2001) The mouse brain in stereotaxic coordinates, Ed 2. San Diego: Academic.

Perea G, Araque A (2007) Astrocytes potentiate transmitter release at single hippocampal synapses. Science 317:1083-1086.

Platt KA, Michaud J, Joyner AL (1997) Expression of the mouse Gli and Ptc genes is adjacent to embryonic sources of hedgehog signals suggesting a conservation of pathways between flies and mice. Mech Dev 62:121-135.

Schummers J, Yu H, Sur M (2008) Tuned responses of astrocytes and their influence on hemodynamic signals in the visual cortex. Science 320:1638-1643.

Sofroniew MV (2009) Molecular dissection of reactive astrogliosis and glial scar formation. Trends Neurosci 32:638-647.
Soriano P (1999) Generalized lacZ expression with the ROSA26 Cre reporter strain. Nat Genet 21:70-71.

Steinhäuser C, Berger T, Frotscher M, Kettenmann H (1992) Heterogeneity in the membrane current pattern of identified glial cells in the hippocampal slice. Eur J Neurosci 4:472-484.

Steinhäuser C, Jabs R, Kettenmann H (1994) Properties of GABA and glutamate responses in identified glial cells of the mouse hippocampal slice. Hippocampus 4:19-35.

Steward O, Torre ER, Tomasulo R, Lothman E (1991) Neuronal activity up-regulates astroglial gene expression. Proc Natl Acad Sci U S A 88:6819-6823.

Stichel CC, Müller CM, Zilles K (1991) Distribution of glial fibrillary acidic protein and vimentin immunoreactivity during rat visual cortex development. J Neurocytol 20:97-108.

Takano T, Tian GF, Peng W, Lou N, Libionka W, Han X, Nedergaard M (2006) Astrocyte-mediated control of cerebral blood flow. Nat Neurosci 9:260-267.

Torre ER, Lothman E, Steward O (1993) Glial response to neuronal activity: GFAP-mRNA and protein levels are transiently increased in the hippocampus after seizures. Brain Res 631:256-264.

Traiffort E, Charytoniuk DA, Faure H, Ruat M (1998) Regional distribution of Sonic Hedgehog, patched, and smoothened mRNA in the adult rat brain. J Neurochem 70:1327-1330.

Traiffort E, Charytoniuk D, Watroba L, Faure H, Sales N, Ruat M (1999) Discrete localizations of hedgehog signalling components in the developing and adult rat nervous system. Eur J Neurosci 11:3199-3214.

Traiffort E, Moya KL, Faure H, Hässig R, Ruat M (2001) High expression and anterograde axonal transport of aminoterminal sonic hedgehog in the adult hamster brain. Eur J Neurosci 14:839-850.

Ullian EM, Sapperstein SK, Christopherson KS, Barres BA (2001) Control of synapse number by glia. Science 291:657-661.

Wallace VA, Raff MC (1999) A role for Sonic hedgehog in axon-to-astrocyte signalling in the rodent optic nerve. Development 126:2901-2909.

Wallraff A, Odermatt B, Willecke K, Steinhäuser C (2004) Distinct types of astroglial cells in the hippocampus differ in gap junction coupling. Glia 48:36-43.

Walz W (2000) Controversy surrounding the existence of discrete functional classes of astrocytes in adult gray matter. Glia 31:95-103.

Wang X, Lou N, Xu Q, Tian GF, Peng WG, Han X, Kang J, Takano T, Nedergaard M (2006) Astrocytic Ca2+ signaling evoked by sensory stimulation in vivo. Nat Neurosci 9:816-823.

Zhang JM, Wang HK, Ye CQ, Ge W, Chen Y, Jiang ZL, Wu CP, Poo MM, Duan S (2003) ATP released by astrocytes mediates glutamatergic activity-dependent heterosynaptic suppression. Neuron 40:971-982.

Zhou M, Kimelberg HK (2001) Freshly isolated hippocampal CA1 astrocytes comprise two populations differing in glutamate transporter and AMPA receptor expression. J Neurosci 21:7901-7908.

Zhuo L, Theis M, Alvarez-Maya I, Brenner M, Willecke K, Messing A (2001) hGFAP-cre transgenic mice for manipulation of glial and neuronal function in vivo. Genesis 31:85-94. 